\title{
EDUCAÇÃO EM CIÊNCIAS E A TEORIA DA ATIVIDADE CULTURAL-HISTÓRICA: CONTRIBUIÇÕES PARA A REFLEXÃO SOBRE TENSÕES NA PRÁTICA EDUCATIVA
}

\author{
Juliano Camillo* \\ Cristiano Mattos**
}

RESUMO: A Teoria da Atividade tem sua origem nos trabalhos de Vigotski e hoje abrange os mais variados campos do saber. Muitas pesquisas no campo da educação em ciências vêm utilizando referências dessa perspectiva, porém, como apontam alguns autores, seu potencial de uso está longe de ser alcançado. Para ampliar a discussão em torno dessa perspectiva teórica, apresentaremos alguns pressupostos da Teoria da Atividade Cultural-Histórica no contexto da educação em ciências. Faremos isso por meio da introdução de três categorias - relação entre o individual e o coletivo, conteúdo da atividade educacional e resultado esperado para a atividade educacional - que permitem explicitar certas tensões que se apresentam nesse tipo de prática educativa e que, segundo nosso ponto de vista, correspondem a contradições que necessitam ser superadas. As questões apresentadas não se esgotam aqui e esperamos que se tornem pontos para futuras discussões em torno dessa temática.

Palavras-chave: Teoria da Atividade. Ensino-aprendizagem. Formação do indivíduo. Lógica dialética.

\section{SCIENCE EDUCATION AND THE CULTURAL-HISTORICAL ACTIVITY THEORY: CONTRIBUTIONS TO THE REFLECTION ON TENSIONS IN EDUCATIONAL PRACTICE}

ABSTRACT: Activity Theory has its origins in the works by Vygotsky and currently spans diverse fields of knowledge. Recently, much of Science Education research have used Socio-Cultural-Historical references, however their potential use is far from being achieved. To broaden the discussion around this theoretical perspective, we present some principles of the Cultural-Historical Activity Theory in the context of Science Education. This is carried out through the making of three explicit categories - the relationship between the individual and the collective, the content of educational activity and the expected result for the educational activity. This allows the clarification of certain tensions that arise in this type of educational practice and, according to our point of view, they correspond to contradictions that need to be overcome. The questions presented here are not exhausted and we expect them to become elements for future debate on this matter.

Keywords: Activity Theory, Teaching and Learning, Subject Formation, Dialectical Logic. 


\section{INTRODUC̣ÃO}

Cada vez mais a pesquisa em ensino de ciências tem se consolidado como campo específico de produção de conhecimento. No Brasil, é crescente o número de publicações em revistas especializadas, de participações em congressos específicos e de teses e dissertações defendidas que abordam a temática do ensino-aprendizagem de conceitos científicos (SALEM, 2012; TEIXEIRA; MEGID, 2012). É crescente também, no Brasil e no resto do mundo, a variedade de referenciais teóricos que dão suporte às análises dos processos de ensino e aprendizagem de ciências (BODNER; ORGILL, 2008; DUIT, 2007; PINTÓ; COUSO, 2007; SALEM, 2012; SANTOS; GRECA, 2008). Além disso, surge, como consequência, o uso de tais reflexões no estabelecimento de políticas públicas, ressaltando a importância do ensino das ciências para a formação de cidadãos (MOURA, 2012; ROTH; DÉSAUTELS, 2004), de profissionais para o mercado de trabalho (AACU, 2013; NACE, 2012; 2013), definindo padrões curriculares do ensino de ciências (AAAS, 2003; ARCHIVE, 2010; NRC, 1996; 2007; OECD, 2006).

Nos últimos anos, muitas investigações sobre o ensino de ciências têm como foco os papéis desempenhados pelas relações sociais e pela linguagem e os processos de significação na sala de aula (MORTIMER; SCOTT, 2003; NASCIMENTO; PLANTIN, 2009), apoiados, muitas vezes, na perspectiva de Vigotski e seus seguidores, no campo da psicologia cultural-histórica, e de Mikhail Bakhtin, no campo da linguagem. Roth (2009), por exemplo, constata que nas duas últimas décadas (de 1989 a 2009) houve um aumento exponencial de trabalhos indexados na ISI Thomson Web of Science com citações dos três maiores expoentes da perspectiva sócio-cultural-histórica: Vigotski, Leontiev e Engeström. No Brasil, Ghelen et al. (2007) mapearam a produção acadêmica, trabalhos apresentados nos Encontros de Pesquisa em Educação em Ciências (ENPEC), que utiliza o referencial vigotskiano e aponta um aumento no número de trabalhos apoiados em Vigotski, o que se deve, segundo os autores, ao também aumento do número de pesquisadores interessados nessa perspectiva teórica.

Lima Junior et al. (in press), por sua vez, realizaram um levantamento de trabalhos publicados na revista Cultural Studies of Science Education que usam Vigotski de acordo com uma perspectiva marxista. Porém, apesar do crescente interesse pela perspectiva sócio-cultural-histórica, tanto no Brasil como no exterior, concordamos com Roth $(2004 ; 2009)$ que tal referencial ainda não foi completamente apropriado pelos pesquisadores no campo da educação em ciências, de maneira que o seu potencial ainda não foi completamente aproveitado, muito menos em uma perspectiva marxista (RODRIGUES et al., 2014). Corroborando com essa posição, Ghelen et al. (2007) apontam que alguns aspectos da teoria vigotskiana têm sido tratados com certa superficialidade, sugerindo uma apropriação inconsistente desse referencial por parte dos grupos de pesquisa em ensino de ciências no Brasil. Segundo Roth (2009), parte das dificuldades encontradas na apropriação dessa perspectiva deve-se à sua ontologia materialista dialética, a qual não permite 
uma fácil integração na lógica formal e não dialética que subjaz grande parte do pensamento vigente na área de ensino de ciências.

Diante desse panorama, colocamos em discussão alguns elementos da Teoria da Atividade Cultural-Histórica que, ao nosso ver, merecem maior espaço de debate e podem trazer contribuições significativas para o campo do ensino de ciências. Isso inclui, por considerarmos fundamental para a análise que aqui fazemos, discutir alguns dos pressupostos filosóficos mais amplos, os quais dão sustentação a tal conjunto teórico e que, muitas vezes, não estão presentes de maneira explícita nos trabalhos de investigação.

Apoiados na Teoria da Atividade, sobretudo em formulações de Vigotski e Leontiev, apontamos categorias teóricas gerais que permitem analisar a prática educativa. A partir delas, discutiremos brevemente como emergem e se manifestam no caso particular e concreto do ensino de ciências as tensões na relação entre o individual e o coletivo; as tensões em torno do conteúdo da atividade educacional e as tensões sobre o resultado esperado para a atividade educacional.

Cabe ressaltar que em um espaço reduzido como o de um artigo, alguns pontos serão apenas enunciados e não aprofundados como mereceriam. Apesar disso, reconhecendo as limitações deste texto, escolhemos assim fazê-lo a fim de trazer para a discussão as potencialidades que o referencial pode proporcionar para futuros e mais aprofundados diálogos em torno da pesquisa em educação em ciências.

\section{TEORIA DA ATIVIDADE ${ }^{1}$}

Vigotski, no começo do século XX, trabalhou na construção de uma psicologia sócio-cultural-histórica, buscando nos métodos de Marx o caminho para o entendimento da mente humana nas suas condições reais de existência. Vigotski fazia crítica às teorias da psicologia que se desenvolviam na mesma época (na Europa e na União Soviética (URSS), especificamente) e que estavam polarizadas entre subjetivismo e objetivismo. Tais correntes analisam o psiquismo separando-o da vida concreta dos sujeitos, que apartam a aprendizagem do desenvolvimento, ou que priorizam somente o desenvolvimento biológico, que dicotomizam o mundo em interior e exterior. Entre as principais contribuições de Vigotski na construção de uma psicologia sócio-cultural-histórica estão os conceitos "formação social da mente", "zona de desenvolvimento proximal", "parceiro mais capaz", entre tantos outros que remetem às dimensões social, cultural e histórica da formação dos indivíduos e fundamentam suas relações com os outros indivíduos e com o mundo na direção de certos objetivos.

Apesar de Vigotski não ter analisado com profundidade a atividade humana, ele entendia, segundo Kozulin (2002, p. 111), que "a atividade socialmente significativa pode servir como princípio explanatório em relação à consciência humana e ser considerada como gerador de consciência humana", ideia que se constitui como uma das teses centrais da Teoria da Atividade, isto é, de que é por 
meio da atividade que a consciência pode emergir e que as potencialidades humanas podem se desenvolver. Dessa forma, atribui-se a Vigotski as origens daquilo que temos chamado de Teoria da Atividade, cujos desdobramentos posteriores se deram, em grande parte, aos esforços de estudiosos como Leontiev e Engeström, que, de certa maneira, ampliaram os trabalhos de Vigotski².

Para melhor delimitar o que chamamos de Teoria da Atividade, é necessário dizer que não há uma teoria unificada sob essa alcunha, tampouco as teses originais de Vigotski formaram, desde sua origem, um corpo teórico coeso e fechado $^{3}$. Além disso, as leituras posteriores dos trabalhos de Vigotski produziram versões com problemas de tradução, versões resumidas, versões que suprimem partes dos originais ${ }^{4}$ e também versões com variados vieses, das quais algumas apresentam teses inconsistentes com as originais. Diferentes interpretações podem trazer avanços significativos à construção do pensamento, entretanto, podem ser danosas quando subvertem alguns dos sentidos intencionados pelo autor.

Deixadas de lado, por ora, as inconsistências nas interpretações da obra de Vigotski, enfatizamos algumas articulações que, de acordo com Holzman (2006, p. 6), podem ser entendidas como caminhos frutíferos para o avanço da referida teoria. Entre tais articulações, apontamos algumas formulações que têm sido chamadas de Teoria da Atividade: o estudo da mente humana em seus contextos culturais e históricos; um sistema conceitual geral com os seguintes princípios básicos: atividade com estrutura hierárquica, orientada a objetos, processo de internalização/externalização, mediação por ferramentas e desenvolvimento/aprendizagem; abordagens teóricas que colocam a atividade e a cultura no centro das tentativas de entender a natureza humana; uma psicologia que se concentra não no indivíduo, mas na interação entre ele, os sistemas de artefatos e outros indivíduos em desenvolvimento; uma abordagem não dualista para a compreensão e transformação da vida humana que toma a atividade humana dialética como sua ontologia.

Apesar de algumas diferenças nessas formulações, elas trazem como ponto comum a tentativa de superação do dualismo presente em uma psicologia em que sujeito e objeto, mundo "interior" (da consciência) e mundo "exterior" (da matéria), estão separados e, de certa maneira, se opõem. Duarte (2002, p. 280) afirma que a Teoria da Atividade é "um desdobramento do esforço por construção de uma psicologia sócio-histórico-cultural fundamentada na filosofia marxista" e que, atualmente, a Teoria da Atividade transcende o campo da psicologia, "abarcando campos como a educação, a antropologia, a sociologia do trabalho, a linguística, a filosofia" (ibidem, p. 280). Davydov, por sua vez, defende que o problema da atividade humana é interdisciplinar por natureza e somente foi formulada primeiramente no campo da psicologia devido às condições históricas que se apresentaram a essa disciplina em particular. Em outras palavras, foi a psicologia que em primeiro lugar deparou-se com os problemas que necessitavam da formulação de uma teoria como a Teoria da Atividade (DANIELS, 2002).

Em suma, a Teoria da Atividade procura analisar o desenvolvimento humano no interior de suas atividades, levando em consideração os aspectos 
psicológicos, antropológicos, sociológicos, históricos e linguísticos (SANNINO et al., 2009). Ela se difere de outras abordagens da mesma escola por tomar como unidade de análise a atividade humana, que seria a menor unidade que contém a complexidade necessária para o entendimento do desenvolvimento humano, não podendo, portanto, ser dividida em elementos menores no processo de análise.

\title{
A ATIVIDADE HUMANA - ABSTRAÇÃO OU UNIDADE DA VIDA REAL?
}

Ao assumirmos a tarefa de trazer para o debate alguns pontos fundamentais da Teoria da Atividade Sócio-Cultural-Histórica é necessário aprofundar, elucidando o que chamamos de "atividade como unidade de análise".

Mais do que um conceito abstrato, a atividade constitui-se da unidade básica da existência humana. É nela e por meio dela que a consciência, a personalidade e as potencialidades tipicamente humanas podem desenvolver-se, que novas condições de existência são originadas, que a realidade é transformada, que contradições são resolvidas e novos artefatos culturais são produzidos (SANNINO et al., 2009). Assim, de acordo com uma perspectiva marxista, é a atividade - produtora e reprodutora da cultura humana - que diferencia o gênero humano das demais espécies puramente biológicas. É pelo processo histórico de construção da cultura que "o gênero humano vai humanizando seu mundo e humanizando a si próprio" (MARKUS citado em DUARTE, 2004, p. 46).

Ao adotar-se a atividade humana como unidade de análise, busca-se levar em conta toda a complexa estrutura cultural e histórica que sustenta, ao mesmo tempo, a formação do indivíduo singular e a formação do gênero humano; processos que não podem ser pensados senão em uma profunda interconexão, uma vez que:

\begin{abstract}
O indivíduo se forma, apropriando-se dos resultados da história social e objetivando-se no interior dessa história, ou seja, sua formação se realiza através da relação entre objetivação e apropriação. Essa relação se efetiva sempre no interior de relações concretas com outros indivíduos, que atuam como mediadores entre ele e o mundo humano, o mundo da atividade humana objetivada. A formação do indivíduo é, portanto, sempre um processo educativo, mesmo quando não há uma relação consciente (tanto de parte de quem se educa, quanto de parte de quem age como mediador) com o processo educativo que está se efetivando no interior de uma determinada prática social. (DUARTE, 1993, p.47-48).
\end{abstract}

Nesse sentido, então, não se pode conceber uma atividade que seja puramente individual (sem relação com o outro), pois mesmo quando um indivíduo realiza isoladamente sua ação, ele a faz mediado pela história humana objetivada e por ele apropriada. Em outras palavras, ao adentrar o gênero humano, um indivíduo não pode ser senão um ser social carregando consigo as marcas daquilo que é tipicamente humano. É o que nos aponta Marx ao falar acerca do desenvolvimento dos sentidos humanos: 
O sentido musical do homem só é despertado pela música. A mais bela música nada significa para o ouvido completamente amusical, não constitui nenhum objeto, porque o meu objeto só pode ser a confirmação de uma das minhas faculdades. Portanto, só pode existir para mim na medida em que a minha faculdade existe para ele como capacidade subjetiva, porque para mim o significado de um objeto só vai até onde chega o meu sentido (só tem significado para um sentido que lhe corresponde). Por consequência, os sentidos do homem social são diferentes dos do homem associal. Só através da riqueza objetivamente desenvolvida do ser humano é que em parte se cultiva e em parte se cria a riqueza da sensibilidade subjetiva humana (o ouvido musical, o olho para a beleza das formas, em suma, os sentidos capazes de satisfação humana e que se confirmam como faculdades humanas). De fato, não são apenas os cinco sentidos, mas também os chamados sentidos espirituais, os sentidos práticos (vontade, amor, etc.), numa palavra, a sensibilidade humana e o caráter humano dos sentidos, que vêm à existência mediante a existência do seu objeto, através da natureza humanizada. A formação dos cinco sentidos é a obra de toda a história mundial anterior. (MARX, 1975, p. 199).

Marx nos aponta, ainda, outro caráter fundamental da atividade humana: a sua orientação aos objetos. Objeto que não é só empírico ou físico, mas é aquele que ganha existência por meio da natureza humanizada e é capaz de orientar a atividade humana sintetizando os motivos que fazem com que os indivíduos se coordenem para alcançar determinado objetivo.

A atividade humana estrutura-se a partir de necessidades, sejam elas do domínio biológico, como saciar a fome e proteger-se do frio, ou de necessidades culturais, como aprender a utilizar uma nova ferramenta para a resolução de um determinado problema. Não surge aqui, em hipótese alguma, uma dicotomização entre necessidades biológicas e necessidades culturais: dada a complexa interconexão que elas podem apresentar, "saciar a fome" pode constituir-se de uma necessidade biológica e primitiva, mas, por outro lado, também se apresenta imbuída de um conteúdo sócio-cultural-histórico.

Enquanto na atividade animal existe uma fusão entre motivo (o que leva a fazer) e objeto (para o que se dirige), na atividade humana as complexas relações entre os envolvidos dá sentido às ações individuais e proporciona a separação ${ }^{5}$ entre objeto e motivo. O objeto é capaz de sintetizar o motivo da atividade. Os indivíduos, ao compartilharem a mesma atividade, estão vislumbrando conjuntamente a possibilidade de, no futuro, saciar suas necessidades - superar as contradições instauradas. Tal moviemento gerará novas necessidades e contradições, o que proporciona a dinâmica da atividade humana.

A separação entre objeto e motivo é bem analisada por Leontiev (2004) em seu exemplo da atividade de caça realizada por um grupo humano primitivo. Ele aponta que a ação daquele indivíduo que espanta o animal, com o intuito de levá-lo a um local onde outros caçadores o possam apanhar, se analisada individualmente, parece contradizer o objetivo geral da atividade que é capturar a presa para saciar a fome. O sentido de sua ação transcende o indivíduo e repousa sobre as complexas relações que se estabelecem entre os envolvidos na atividade. Desde o início do processo de humanização, o trabalho ${ }^{6}$ tem sido responsável pela também produção de relações sociais. 
Ainda segundo Leontiev (2004), a atividade é constituída por ações e operações que em diferentes níveis coordenam-se para gerar um nível superior na hierarquia. As operações (relacionadas às condições instrumentais), quando coordenadas, geram ações (com fins específicos) e estas, quando coordenadas, compõem a atividade (com seu motivo) (Figura 1).

Figura 1: A estrutura da Atividade Humana

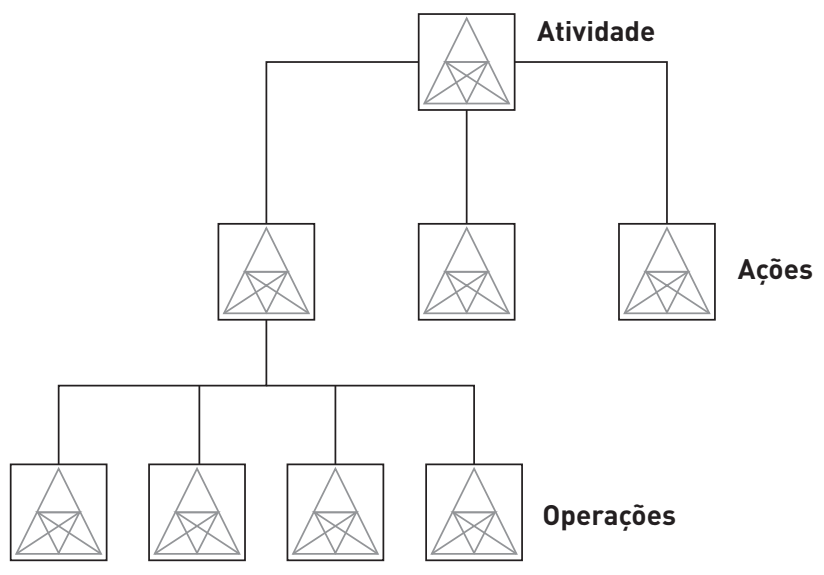

Destacamos que a estruturação da atividade não se dá por uma simples lógica causal: operações coordenadas geram ações, que, por sua vez, coordenadas, compõem a atividade. Os diferentes níveis interpenetram-se, retroalimentam-se e determinam-se reciprocamente, ou seja, apesar de a atividade ser composta na coordenação de ações e operações, é ela que determina e é determinada pelo contexto para que a coordenação possa acontecer. As operações constituem-se de atividades já internalizadas - realizadas de maneira mais automática, ou seja, realizadas sem a necessidade de deter-se atentamente a elas. Cada ação ou operação, em diferentes níveis da hierarquia, estão coordenadas de modo que dependendo do nível da análise, os níveis hierárquicos operação, ação e atividade podem ser entendidos como níveis hierárquicos inferiores ou superiores de outras atividades vinculadas, revelando diferentes graus de complexidades do objeto de análise (DALRI et al., 2009).

\section{A COGNIC̣ÃO COMO ASCENSÃO AO CONCRETO}

Diante da complexidade apresentada pela atividade humana e apoiados na tese de que a atividade e a mente humanas determinam-se recíproca e dialeticamente, não poderíamos esperar senão uma estrutura também complexa para o processo de ensino-aprendizagem e de construção do conhecimento, também marcado por contradições e suas superações - as sínteses dialéticas. 
Na perspectiva do materialismo dialético, a construção do conhecimento se dá pelo contínuo movimento de redução do concreto imediato ao abstrato e ascensão ao concreto real, complexificado. O concreto passa a ser entendido, sob essa lógica, o início e o fim de todo o processo, mediado por um elo intermediário de abstração, visto como uma redução, uma vez que isola elementos do concreto primitivo (sensório) para transformá-los por meio da atividade da práxis. A verdadeira ascensão reside na volta ao concreto real, qualitativamente diferente do primeiro concreto (sensório), no qual se fazem presentes toda a complexidade e as contradições inerentes à realidade humana (ILYENKOV, 2004).

É neste sentido, que Pazello e Mattos (2010) e Santos (2011), apoiados em Vigotski, Davydov e Ilyenkov, defendem que o processo de formação de conceitos não se constitui da construção de abstrações puras, tampouco da busca de formas cada vez mais descontextualizadas e independentes da atividade humana, mas de articulações cada vez mais complexas com o real:

Assim, o concreto é visto por Vigotski não só como ponto de partida, mas também como destino do abstrato. Tal ideia entra em choque com visões da lógica clássica, uma vez que confere ao concreto um status ontologicamente diferente do sensorial mundano. Em outras palavras, sendo a realidade vigotskiana concreta, a formação de conceitos deveria ter como objetivo articular-se com tal realidade. Para Vigotski, a abstração vista por si só não constituiria um estágio "mais elevado" de cognição, uma vez que seria a partir de abstratos (contextos particulares) que se chegaria ao concreto (múltiplos contextos). Dessa forma, considerar o homem como um ser rodeado por contradições, as quais seriam a própria mola propulsora de sua existência, é entender sua vida como uma relação dialética com a história. O homem faz e é feito por interações histórico-culturais e, dessa forma, se transforma ad infinitum. (PAZELLO; MATTOS, 2010, p.4).

Isso leva os autores a associar processo de formação de conceitos ao processo de generalização, não no sentido de indução empirista, como a lógica clássica entende, mas um processo mais bem caracterizado por uma hipercontextualização, pelo qual os conceitos são mais complexos à medida que se articulam com mais contextos (e não com menos) e se entrelaçam cada vez mais com a realidade da práxis humana.

Rodrigues e Mattos (2007) e Rodrigues (2009) estabelecem relações entre a complexidade dos sentidos e o que chamam de ordens de aprendizagem. O conceito é visto como um perfil com múltiplos sentidos que dependem dos contextos que o sujeito vivencia. Uma maior ordem de aprendizado implica em um maior reconhecimento, por parte do sujeito, dos contextos nos quais o conceito (sentido) é utilizado (se manifesta).

Neste sentido, os conceitos não são entidades desprovidas de realidade, mas são eles próprios construtores/articuladores da realidade que se abre diante da atividade da práxis. Pois, como afirma Leontiev (2004), um conceito não perde sua objetividade quando passa a ser um conceito de uma pessoa, tampouco existe um reino platônico de significações fora do mundo real. Nesse sentido, o processo de formação de conceitos é bastante mais complexo do que a simples transmissão 
de entidades ontologicamente independentes da atividade humana. É o que leva Vigotski a apontar que:

\begin{abstract}
Não menos que a investigação teórica, a experiência pedagógica nos ensina que o ensino direto de conceitos sempre se mostra impossível e pedagogicamente estéril. O professor que envereda por este caminho costuma não conseguir senão uma assimilação vazia de palavras, um verbalismo puro e simples que estimula e imita a existência dos respectivos conceitos na criança, mas na prática, esconde o vazio. (...) No fundo, esse método de ensino de conceitos é a falha principal do rejeitado método puramente escolástico de ensino, que substitui a apreensão do conhecimento vivo pela apreensão de esquemas verbais mortos e vazios. (VIGOTSKI, 2001, p. 247).
\end{abstract}

Leontiev (2004) defende que o processo de apropriação das objetivações humanas ocorre sempre no interior de atividades que reproduzem os traços essenciais da atividade acumulada no objeto. Quando falamos da educação formal (e intencional, no interior de uma instituição com especificidades e características históricas, à qual foi atribuída pela sociedade tal função de educar), a escola passa a ser entendida como espaço de efetivação dessas atividades nas quais os alunos devem se engajar a fim de se apropriarem das objetivações humanas e atribuírem novos sentidos diante do já construído - é também a escola o espaço para o novo.

Assim, cabe à escola o papel de identificar e selecionar um conjunto de objetivações humanas, produzidas historicamente, consideradas fundamentais para compor as atividades educacionais, realizáveis no tempo e espaço escolares, importantes para cada realidade escolar. Mais do que identificar e selecionar, é também papel da escola o reconhecimento da melhor forma de efetivação dessas atividades, o que depende das especificidades dos saberes que se pretende ensinar (filosofia das ciências, por exemplo) e dos processos específicos pelos quais pode-se ensinar-aprender (teorias de aprendizagem, por exemplo). Ressalta-se, assim, a complexidade do fenômeno educacional, que não pode estar apoiado simplesmente no campo do saber específico (o da Física, Química ou Biologia, por exemplo), mas também nos campos da psicologia, antropologia, filosofia etc.

Se efetivadas as condições para a realização da atividade educacional, os sujeitos podem se tornar, ao mesmo tempo, construtores de sua individualidade e do gênero humano. A educação passa a ser, então, mediadora entre aquilo que os indivíduos são e o que podem vir-a-ser.

\title{
CONTRIBUIC̣ÕES PARA A REFLEXÃO SOBRE A EDUCAC̣ÃO EM CIÊNCIAS
}

As categorias, que agora faremos explícitas e que guiam nossa discussão em torno da prática educativa (no caso particular do ensino de ciências), estiveram presentes, implicitamente, ao longo do exposto até aqui - fazê-las explícitas, neste momento, tem o papel de facilitar a discussão e o aprofundamento posteriores. Tais categorias, oriundas do modelo teórico e aqui concretizadas, são capazes de 
representar tensões que se manifestam na prática educativa e que muitas vezes são tratadas de forma dicotômica, isto é, mantendo a discussão em torno de duas ideias contraditórias que se situam em extremos opostos. A eliminação da tensão, em uma lógica reducionista, reside na supressão de um dos polos que gera a tensão. Buscamos, assim, por meio da dialética que subjaz a Teoria da Atividade, trazer contribuições para a reflexão sobre tais dicotomias, sem que o caminho seja, necessariamente, a eliminação de um dos polos, nem situar-se no meio do caminho entre as duas posições contraditórias, mas, pela síntese, capaz de gerar uma atividade qualitativamente nova. Não significa, no entanto, que este trabalho oferece caminhos já prontos para a superação de tais dicotomias, mas, ao contrário, apresenta subsídios para pensá-las nas práticas concretas que se efetivam no ensino de ciências.

A primeira categoria expressa a relação entre o individual e o coletivo. Nela emergem diferentes tensões, como aquela entre o sentido pessoal e sentido coletivo (significado), entre os interesses individuais/locais e os coletivos/gerais ou, ainda, entre a formação do indivíduo e suas formas de participação na coletividade. Essa é uma categoria relacionada com o sujeito da atividade educacional.

A segunda categoria explicita a tensão acerca do conteúdo da atividade educacional. Por exemplo, representa, no processo educacional, a oposição entre os resultados da ciência e seus processos, ou seja, entre o ensino da ciência como uma descrição da realidade ou como um processo pelo qual o conhecimento sobre a realidade pode ser produzido (MATTOS, 2010).

A terceira categoria exprime a tensão gerada em torno do resultado esperado para a atividade educacional. Esta se expressa, no processo educacional, na oposição entre a apropriação do conhecimento já estabelecido e a construção de novos conhecimentos.

Essas não são três categorias independentes, uma vez que cada uma delas está também presente nas outras. Ao planejar uma atividade educacional, ter um objetivo, uma escolha específica para o sujeito, implica, também, em uma escolha para o resultado e conteúdo; uma escolha específica para o resultado implica numa escolha de sujeito e conteúdo, e assim por diante. De posse das categorias gerais, partimos para a discussão do caso concreto do ensino de ciências.

\section{O SUJEITO DA ATIVIDADE: INDIVIDUAL VERSUS COLETIVO}

São muitos os que afirmam que a educação em ciências vive permanentemente uma crise, e que no coração dessa crise há uma questão do sentido atribuído à ciência (FOUREZ, 2003; SMITH, 2010). Por um lado, professores e escolas, dirigidos por currículos tradicionais, preferem conteúdos relacionados ao mundo da ciência, por outro, alunos buscam, na escola, conteúdos ligados ao seu cotidiano (FOUREZ, 2003). Além disso, a sociedade moderna espera que os estudantes possam ser diretamente preparados para o mercado de trabalho, desenvolvendo 
competências gerais e sendo flexíveis, de maneira a se adaptar às novas demandas (AACU, 2013; LACK, 2005), enquanto estudantes esperam uma educação científica que possa explicar-lhes o seu próprio mundo. Como defendido por Fourez (2003), isso não significa que os estudantes desejem permanecer presos ao seu próprio universo, mas, ao contrário, eles não querem uma educação sem significado algum para si mesmos e para o próprio mundo. Além disso, os estudantes parecem temer a imposição da visão de mundo da ciência sobre eles, como sendo a única possível.

Abordagens educacionais, quando inseridas em uma perspectiva construtivista radical ${ }^{7}$, conduzem à ideia de que o conhecimento construído individualmente é mais valioso que outras formas, como o conhecimento já estabelecido pelo gênero humano ao longo de sua história - o que caracteriza uma supervalorização da aprendizagem individual por meio do processo de descoberta. Nessa perspectiva, a atividade educacional está centrada na atividade espontânea dos indivíduos, nas suas aspirações particulares unicamente.

Por outro lado, fez-se muito presente, no ensino de ciências, por exemplo, nas atividades dos projetos da era das reformas pós-Sputnik (Biological Sciences Curriculum Study, Chemical Education Material Study e Physical Science Study Committee), a ideia de que "o conhecimento pode ser melhor ou apenas aprendido por meio da experiência que se baseia nos procedimentos da disciplina” (KIRSCHNER; SWELLER, 2006, p. 84), independente dos interesses mais específicos dos estudantes e sem relação direta com a realidade existencial. Tem-se, assim, a supressão do indivíduo diante de um processo coletivo cristalizado, de um suposto método universal ao qual os indivíduos devem submeter-se caso busquem produzir conhecimento sobre a realidade.

Lidar com a tensão entre o indivíduo e o coletivo de forma não dialética significa, como já dito, tentar suprimir um dos polos que gera a tensão a fim de evitá-la. Por um lado, é possível conceber um indivíduo abstrato que é completamente independente do coletivo no qual está inserido. Sob esse ponto de vista, a coletividade seria resultado da qualidade natural dos indivíduos de socializar-se ${ }^{8}$, um conjunto de indivíduos justapostos. Por outro, a individualidade humana pode ser concebida como uma reprodução mecânica das características gerais da sociedade.

Dialeticamente, a relação entre tais polos não se dá apenas por uma lógica indutiva ou dedutiva: o coletivo não é simplesmente um conjunto de indivíduos. É qualitativamente diferente da soma de seus constituintes, uma vez que eles têm, simultaneamente, qualidades genéricas da humanidade e experiências singulares que os constituem - são dialeticamente genéricos e singulares. A humanidade não pode ser reduzida ao indivíduo, nem o indivíduo reduzido à humanidade. Nesse sentido, não há completa oposição entre indivíduo e coletivo.

Como já discutido anteriormente, as relações mediadas entre os indivíduos, na atividade, são capazes de fazer emergir a consciência humana, que por sua vez permite relações mais e mais complexas e, assim, formas mais complexas de consciência ao longo da história. Se, por um lado a complexificação da atividade 
pode conduzir a formas mais críticas de consciência, de apropriação do gênero humano e da individualidade humana (que chamaremos de humanização), por outro pode implicar na completa separação entre os indivíduos e o fruto da sua atividade, do seu trabalho. $\mathrm{O}$ motivo para o engajamento na atividade pode ser completamente separado do seu conteúdo real; os indivíduos são privados de se objetivar por meio da sua atividade (o que chamaremos de alienação) e negados de construir sua real e livre individualidade - que somente pode ocorrer à medida que a humanidade se torna coletivamente livre.

$\mathrm{Na}$ ciência e, consequentemente, na sua educação, podemos considerar dois níveis hierárquicos que se retroalimentam. O primeiro é a agenda de produção da ciência que está alinhada socioeconomicamente, seja a problemas humanos globais, como a fome, as doenças e a pobreza, mas, também, muitas vezes, está ligada a fins mais imediatos e capitalistas, cujo foco é a geração de lucro. Nesse último fim, emerge, na produção científica, a oposição entre as necessidades reais dos indivíduos e os interesses mais particulares de partes da sociedade capitalista. O segundo nível é a apropriação e a objetivação da ciência pela sociedade. Mesmo quando relacionada a verdadeiras necessidades humanas, a ciência pode assumir a forma de mercadoria, ganhando, aparentemente, uma realidade independente (separada da atividade humana - o fetichismo da mercadoria), servindo como meio de opressão e de oposição entre indivíduo e coletivo. Isto é, a ciência, quando tomada como conhecimento fetichizado, não é capaz de promover consciência crítica nem de promover transformações sociais que expressem as reais necessidades da sociedade que a sustenta. A ciência, nessa forma, se encontra fora da práxis humana mais geral e dos processos concretos nos quais os indivíduos vivem.

\section{O CONTEÚDO DA ATIVIDADE: EPISTEMOLOGIA VERSUS ONTOLOGIA}

Historicamente, o ensino de ciências tem sido pensado por meio da relação entre produtos e processos científicos, em outras palavras, entre o que sabemos (resultados científicos) e como sabemos (formas de saber) (DUSCHL, 1990). Tradicionalmente, a educação científica tem, principalmente, focado no que sabemos, em detrimento de como sabemos, enfatizando os resultados da ciência em vez de seus processos de produção. Ou seja, o ensino de ciências, na grande maioria das situações escolares, dá ênfase aos conteúdos, ou seja, está focado apenas nos resultados científicos (MOREIRA, 2000).

Um exemplo disso é o ensino da física experimental. Experimentos são tomados como receitas para atingir resultados previamente determinados. Assim, sob esse ponto de vista, a ciência é ensinada como uma ontologia, uma simples descrição de como são as coisas do mundo (CAMILLO, 2011), isto é, a ciência é apresentada como um conjunto de resultados, sem discutir os métodos que lhes dão suporte, ou, algumas vezes, como um método supostamente universal, que é independente de contextos específicos e dos resultados ali alcançados. A síntese 
entre produção e consumo da ciência não é possível nesse modo de representação dessa atividade humana, implicando nos limites da pesquisa científica e, consequentemente, na perda de relações mais amplas, como as dimensões ética e política.

Entretanto, há algum tempo vem crescendo o consenso (e as tentativas de mudança das práticas educacionais) sobre a importância de se ensinar "formas científicas de pensar" (YANG, 2004), enfatizando, também, os processos de conhecer, e permitindo o exercício da construção de novos conhecimentos. Nesse sentido, uma abordagem na educação em ciências, que tem como objetivo ensinar integralmente o conhecimento socialmente estabelecido e seus métodos de produção, difere radicalmente de abordagens centradas no ensino do conhecimento científico como verdades acabadas.

Para além da relação entre métodos e resultados, pesquisas têm mostrado que os resultados científicos estabelecidos e os modos científicos de pensar a eles relacionados não se tornam os elementos determinantes na tomada de decisões de estudantes ou de cidadãos em geral, seja sobre questões relativas ao conhecimento científico, seja sobre questões sociopolíticas. Nielsen (2012, p. 276) argumenta que a informação científica, ou o conhecimento científico, nunca pode, por si só, autorizar ou justificar uma decisão que depende de valores; afirma que muitas decisões sobre questões sociais tendem a ser, apenas, decisões valorativas. Por exemplo, Gough et al. (2009) apontam que os jovens, mesmo sabendo dos riscos do tabagismo, parecem mais preocupados com questões financeiras, defendendo que, atualmente, muitas coisas além do cigarro fazem mal à saúde e que fumar pode efetivamente ser usado para aliviar o stress. Yang e Anderson (2003) mostram que os estudantes do Ensino Médio podem facilmente ser afetados por fatores emocionais quando estão avaliando evidências científicas. Assim, verifica-se que estudantes, mesmo os jovens adultos, têm exibido incapacidade de usar o raciocínio científico em questões sociais no contexto de vida, apesar de apresentarem tais habilidades em situações específicas nas quais o seu domínio é obrigatório (BASTOS; MATTTOS, 2009a; SODRÉ; MATTTOS, 2013; YANG, 2004). Isso é um claro indício da dificuldade de recontextualização de habilidades de raciocínio, explicitando os conflitos entre uso do raciocínio científico na escola e em diferentes contextos sociais (BASTOS; MATTOS, 2009b; BASTOS, 2011).

Esses exemplos podem sugerir que a educação em ciências deve ser concebida para além da relação o que nós sabemos/como nós sabemos a fim de englobar outras dimensões como a de valor e fim do conhecimento, como sugerido por Bastos e Mattos (2009b) ao introduzirem, além da epistemologia e ontologia, a axiologia. O objetivo disso é compreender a complexidade da tomada de decisão sobre questões com conteúdo científico.

Outra faceta dicotômica relaciona-se à já criticada elevação da abstração como estágio final do processo de construção do conhecimento. Como vimos, essa é uma ideia fetichizada de que elementos mais abstratos implicam em conhecimentos mais gerais, enquanto os mais complexos incidem sobre a realidade concreta. Ilyenkov (2009, p. 107) argumenta contrariamente que: 
"pensar abstratamente significa ser escravizado pela força de bordões e clichês, de definições vazias e unilaterais; significa ver no real as coisas sensivelmente intuídas apenas numa parte insignificante de seu conteúdo real, apenas algumas determinações como se já fossem cristalizadas na consciência e funcionado como estereótipos prontos".

Nessa perspectiva - de tomar a abstração como um fim em si mesma e último estágio no processo de construção do conhecimento -, a atividade educacional assume o papel de fazer com que os indivíduos se apropriem, tanto de formas de conhecimento, como de formas de construir conhecimento, cada vez mais abstratas. Dessa maneira, as formas são cada vez mais afastadas da realidade e mais vazias de conteúdo concreto. No caso específico da educação em ciências, tal fetichização da abstração está presente quando se assume uma oposição entre os conceitos cotidianos e os conceitos científicos. Conceitos científicos adquirem o status de conhecimento mais abstrato, uma vez que poderiam ser aplicados a uma variedade maior de situações, enquanto os conceitos cotidianos são tratados como forma indesejável de conhecimento, como erro, cuja eliminação deve ocorrer para dar lugar aos conhecimentos científicos. Assim, ignora-se tanto o complexo processo de evolução do conhecimento sistemático alcançado pela humanidade ao longo da sua história - o conhecimento científico -, visto que científico e cotidiano historicamente se interpenetram, quanto a ideia defendida por Vigotski (2001) de que o processo de formação de conceitos (ensino-aprendizagem) se dá na relação entre os conteúdos concretos e vivenciados pelos indivíduos e as formas sistematizadas de conhecimentos, e não na exclusão de um deles.

Nesse sentido, como proposto por Ilyenkov (2009) e explorado por Pazello e Mattos (2010), um conhecimento mais geral é, portanto, mais concreto, mais capaz de apreender e transformar a realidade nas suas múltiplas determinações ${ }^{9}$.

\section{O RESULTADO DA ATIVIDADE EDUCACIONAL: DETERMINISMO VERSUS LIBERDADE}

A tensão que aqui explicitamos expressa uma questão fundamental dentro da prática educativa: seria a apropriação do conhecimento já estabelecido um processo que leva os indivíduos à alienação e ao determinismo, que os limitaria a tornarem-se mero produto do seu meio cultural, sem consciência crítica? Estaria a verdadeira liberdade associada ao processo de experimentar as coisas por si só, vivenciar o mundo de maneira livre e independente - uma espécie de negação da experiência humana passada? Nessa perspectiva, o conhecimento produzido de maneira independente pelo indivíduo teria mais valor que o conhecimento acumulado pela humanidade?

A interdependência das categorias se faz mais aguda aqui, quando temos a necessidade de retomar à discussão sobre humanização e alienação iniciada na análise na primeira categoria, assim como à discussão da própria natureza do conhecimento, como discutido na segunda categoria. Dessa forma, a análise da tensão acerca do produto da atividade educacional deve considerar que a própria tensão está diretamente relacionada ao consumo e à produção da ciência. 
A ciência, como toda atividade humana entendida dentro da categoria do trabalho, ou seja, uma atividade humana transformadora do e transformada pelo mundo, é capaz de objetivar/sintetizar formas especificamente humanas, que podem ser apropriadas pelos indivíduos a fim de que se humanizem. Nesse sentido, a apropriação das aptidões humanas historicamente formadas é componente essencial no processo de constituição do indivíduo humano e do gênero humano - objetos da cultura humana são convertidos em instrumentos de individualidade.

No entanto, em uma sociedade capitalista, os indivíduos podem ser privados de se apropriarem das conquistas humanas historicamente formadas, sobretudo quando a educação (e a ausência de uma concepção de educação libertadora) serve como método de (re)produção da estrutura alienada e alienante, ou seja, como um processo no qual os indivíduos são levados a adaptar-se às condições a eles impostas sem que tenham caminhos para a crítica de tal estrutura, sem que deixem de ser apenas consumidores de produtos fetichizados para se tornarem agentes ativos no fluxo produtivo da história humana. Assim, a relação entre objetivação e apropriação, em vez de ser concebida unicamente como alienadora, é um processo pelo qual as potencialidades humanas são alcançadas - seu devir: contínuo e interminável processo por meio do qual se produz e reproduz o indivíduo singular e a humanidade como gênero.

Nesse sentido, o papel da educação é o de proporcionar ao educando o enriquecimento e a complexificação das relações que estabelece com o mundo, fazendo com que se aproprie do já estabelecido e, dialeticamente, proporcionando caminhos para a criação do novo a partir do já dado. Tal caminho jamais se constrói por meio da substituição das relações que o sujeito estabelece previamente com o mundo, nem por meio do apagamento da sua individualidade frente à necessidade de uma homogeneização que a educação em massa vem apregoando, nem pelo conformismo diante da realidade problemática que lhe é imposta. Tal caminho transforma a realidade problemática em problemas significativos, cujas soluções estão coordenadas com os vários níveis hierárquicos das vidas dos sujeitos (GEHLEN; MATTOS, 2009).

Dialeticamente alienação/emancipação, bem como consumo/produção, são faces do processo de transformação/conservação do gênero humano, por meio do qual os seres humanos tornam-se humanos, reproduzindo/criando objetos/instrumentos de relação com o mundo. Nesse sentido, ser alienado e emancipado é uma condição histórica humana - superar alienações por meio de emancipações é lidar com uma realidade cada vez mais complexa, um novo concreto que traz outras alienações e outras formas de emancipações, contínuo processo do devir humano.

\section{CONCLUSÃO}

Buscamos, então, neste trabalho, ainda que de maneira inicial, fazer uma discussão em torno de alguns princípios que norteiam uma concepção histórica de 
desenvolvimento humano, de produção do conhecimento, de processo educativo, de transformação da realidade e outros elementos que não podem ser concebidos de maneira independente ou desarticulada, quando buscamos analisar a práxis humana ou, de maneira específica, a práxis educacional.

Diante desse panorama, entendemos que o processo de formação do ser humano e os processos de ensino-aprendizagem estão longe de serem triviais. De posse de três categorias, não únicas e nem excludentes entre si, buscamos discutir tensões que se fazem presentes na atividade educacional.

Discutimos que manifestam-se, no indivíduo particular, por meio de apropriações no interior das atividades, as potencialidades do gênero humano, acumuladas ao longo da história, fazendo com que o ser humano seja, ao mesmo tempo (e dialeticamente), um ser genérico e singular, universal e particular, pois, de um lado, a experiência humana objetivada garante a estabilidade de certos significados, por outro, o momento único da experiência vivida por cada sujeito proporciona sentidos únicos e o constitui como ser singular. Ao tomar como sua tais riquezas do gênero humano e constituir-se por meio delas de maneira não alienada, é possível ao sujeito a construção do novo a partir do já dado e, assim, torna-se viável a transformação da realidade humana. Para além da relação entre conteúdos e métodos, o processo de conhecer e transformar a realidade incorpora outras dimensões, como a a valorativa, a ética e a política.

Compreendemos que lançar um olhar por meio da Teoria da Atividade (ou sob qualquer outra ótica não reducionista, isto é, que consiga captar a dinamicidade e complexidade do fenômeno educacional), sobre o ensino de ciências, não é um projeto trivial. É uma tarefa árdua e necessariamente um processo coletivo que, segundo nosso ponto de vista, é valioso de ser feito. Buscamos, aqui, estabelecer um diálogo sobre as muitas questões em torno dessa temática, que ainda estão abertas e merecem maior atenção e aprofundamento conceitual se desejarmos proporcionar melhorias na educação em ciências. Esperamos que as questões apresentadas, que de maneira alguma aqui se esgotam, sejam encaminhamento de futuras discussões em torno dessa temática.

\section{AGRADECIMENTOS}

Cristiano Mattos agradece ao CNPq por bolsa de produtividade em pesquisa nível 2 (n. 303870/20125), por financiamentos de projetos de pesquisa. Juliano Camillo agradece à CAPES pelo financiamento do projeto de pesquisa que derivou o presente artigo.

\section{NOTAS}

${ }^{1}$ É interessante deixar claro, logo no início, que a questão da nomenclatura é bastante problemática. Pode-se dizer com bastante certeza que não existe uma única Teoria da Atividade. Porém, o modelo que tornou-se mais famoso foi aquele formulado por Engeström (1987). Em geral, quando se fala 
em Teoria da Atividade se remete quase imediatamente ao que Engeström, referindo-se ao próprio trabalho, chamou de Terceira Geração, como sucessão do que ele chamou de Segunda Geração (formulada por Leontiev) e Primeira Geração (formulada por Vigotski). Situamo-nos, portanto, neste trabalho, fora das denominações dadas por Engeström. Concentramo-nos em explorar o conceito de Atividade em Vigotski e Leontiev, em uma concepção predominantemente marxista, naquilo que diz respeito aos processos de desenvolvimento humano.

${ }^{2}$ Para maiores detalhes, consultar DUARTE (2007).

${ }^{3}$ Acerca dessa discussão, ver, por exemplo, Daniels (2002), Kozulin (2002) e Holzman (2006).

${ }^{4}$ Daniels (2002), por exemplo, aponta que na primeira versão em inglês de Tought and Language foram suprimidas todas as referências a Marx. A tradução daquela obra (VIGOSTSKI, 1987) é a versão na qual está baseada grande parte das publicações brasileiras que utilizavam Vigotski como referencial no início dos anos 1990. Em 2001 foi publicada A construção do pensamento e da linguagem (VIGOTSKI, 2001), com tradução da obra completa feita diretamente do russo para o português.

${ }^{5}$ Em um sistema econômico como o capitalista, por exemplo, existe uma ruptura tão grande entre as ações individuais e o objeto da atividade que o sujeito não é capaz de se reconhecer no processo histórico de produção. Passa a existir um abismo entre aquilo que motiva suas ações (receber salário em troca da sua força de trabalho, por exemplo) e o produto final de sua atividade (um produto ou o lucro do capitalista, por exemplo).

${ }^{6} \mathrm{Na}$ concepção marxista: "Antes de tudo, o trabalho é um processo entre o homem e a Natureza, um processo em que o homem, por sua própria ação, media, regula e controla seu metabolismo com a Natureza. Ele mesmo se defronta com a matéria natural como uma força natural. Ele põe em movimento as forças naturais pertencentes à sua corporalidade, braços e pernas, cabeça e mão, a fim de apropriar-se da matéria natural numa forma útil para sua própria vida. Ao atuar, por meio desse movimento, sobre a Natureza externa a ele e ao modificá-la, ele modifica, ao mesmo tempo, sua própria natureza. Ele desenvolve as potências nela adormecidas e sujeita o jogo de suas forças a seu próprio domínio.” Marx (1982, p. 112).

${ }^{7}$ Para maiores detalhes sobre análise das abordagens construtivistas, consultar DUARTE (2000).

${ }^{8}$ Aqui reside a crítica de Marx sobre a naturalização do histórico, ou seja, a crítica às tentativas de se explicar os mecanismos sociais por meios naturais, ignorando a ontologia completamente nova que se abre diante do trabalho, tipicamente humano, que conduz a leis qualitativamente diferentes das naturais. Isso não significa que existe uma ruptura completa entre o biológico, físico, químico e o social, mas que este último não pode ser reduzido àqueles.

9 Para Marx: "O concreto é concreto porque é a síntese de múltiplas determinações e, por isso, é a unidade do diverso. Aparece no pensamento como processo de síntese, como resultado, e não como ponto de partida, embora seja o verdadeiro ponto de partida, e, portanto, também, o ponto de partida da intuição e da representação. No primeiro caso, a representação plena é volatilizada numa determinação abstrata; no segundo caso, as determinações abstratas conduzem à reprodução do concreto pela via do pensamento. Eis por que Hegel caiu na ilusão de conceber o real como resultado do pensamento que, partindo de si mesmo se concentra em si mesmo, se aprofunda em si mesmo e se movimenta por si mesmo; ao passo que o método que consiste em elevar-se do abstrato ao concreto é, para o pensamento, apenas a maneira de se apropriar do concreto, de o reproduzir na forma de concreto pensado; porém, não é este de modo nenhum o processo de gênese do concreto em si” (MARX, 1859). 


\section{REFERÊNCIAS}

AAAS - American Association for the Advancement of Science. Benchmark for science literacy. New York: Oxford University Press, 2003.

AACU - Association of American Colleges and Universities. It takes more than a major: employer priorities for college learning and student success. Washington, DC: Hart Research Associates, 2013.

ACHIEVE - International science benchmarking report. Taking the lead in science education: Forging next-generation Science standards. Washington, DC. 2010. Disponível em: <http://www.achieve. org/files/InternationalScienceBenchmarkingReport.pdf> Acesso em: 2014-02-12.

BASTOS, P.W. A ciência complexificando o conhecimento cotidiano: uma intervenção na escola pública. 2011. 413f. Tese (Doutorado em Ensino de Física) - Ensino de Ciências (Física, Química e Biologia), Universidade de São Paulo, São Paulo, 2011. Disponível em: <http://www.teses.usp.br/teses/ disponiveis/81/81131/tde-30052012-155511/> . Acesso em: 12 fevereiro 2014.

BASTOS P. W.; MATTOS C.R. Um exemplo da dinâmica do perfil conceitual como complexificação do conhecimento cotidiano. Revista Electrónica de Enseñanza de las Ciencias, Vigo, Espanha, v. 8, n. 3, p. 1054-1078, 2009a.

. Física para uma saúde auditiva. Revista Brasileira de Pesquisa em Educação em Ciências, São Paulo, v. 9, p. 1-26, 2009b.

BODNER, G.M.; ORGILL, M.K. Theoretical Frameworks for Research in Chemistry/Science Education. New York: Prentice Hall, 2008.

CAMILLO, Juliano. Experiências em contexto: a experimentação numa perspectiva sócio-cultural-histórica. 2011. 175f. Dissertação (Mestrado em Ensino de Física) - Ensino de Ciências (Física, Química e Biologia), Universidade de São Paulo, São Paulo, 2011. Disponível em: < http://www.teses.usp.br/ teses/disponiveis/81/81131/tde-31052012-104321/>. Acesso em: 12 fevereiro 2014.

DALRI, J., RODRIGUES, A.M., MATTOS, C.R. A atividade de aprendizagem, a internalização e a formação de conceitos no ensino de física. In: Simpósio Nacional de Ensino de Física, 17., 2007. São Luís. Atas... São Luís: Sociedade Brasileira de Física, 2007.

DANIELS, H. Introdução: a psicologia num mundo social. In: Vygotsky. São Paulo: Loyola, 2002. p. 1-30.

. (Org.). Uma introdução a

DESAUTELS, J. Educating for citizenship: Reappraising the role of science education. Canadian Journal of Science, Mathematics and Technology Education, v. 4, n. 2, p. 149-168, 2004.

DUARTE, N. (Org.). Sobre o construtivismo. Campinas: Autores Associados, 2000.

- A teoria da atividade como uma abordagem para a pesquisa em educação. Perspectiva, Florianópolis, v. 20, n. 2, p. 279-301, jul./dez. 2002.

. Educação escolar, teoria do cotidiano e a escola de Vygotsky. São Paulo: Autores Associados, 2007.

Education as mediation between the individual's everyday life and the historical construction of society

and culture by bumankind. In: SAWCHUK, P.; DUARTE, N.; ELHAMMOUMI, M. (Eds.). Critical perspectives on activity theory: explorations across education, work, and everyday life. Cambridge University Press, 2006. p. 211-237.

Formação do indivíduo, consciência e alienação: o ser humano na psicologia de A. N. Leontiev. Caderno CEDES, Campinas, v. 24, n. 62, p. 44-63, 2004.

DUIT, R. Science Education Research Internationally: Conceptions, Research Methods, Domains of Research. Eurasia Journal of Mathematics, Science \& Technology Education, v. 3, n. 1, p. 3-15, 2007.

DUSCHL R. Restructuring Science Education: the role of theories and their importance. New York: Teacher's College Press, 1990.

ENGESTRÖM Y. Expansive Learning at Work: toward an activity theoretical reconceptualization. Journal of Education and Work. v. 14, n. 1, p. 133-156, 2001.

FOUREZ G. Scientific and Technological Literacy as a Social Practice. Social Studies of Science. v. 27, n. 6, p. 903-936, 1997.

. Crisis in science teaching? Investigações em Ensino de Ciências, Porto Alegre, v. 8. n. 2, p. 109123, 2003. 
GEHLEN, S; MATTOS, C.R. Freire e Leontiev: contribuições para o ensino de ciências. In: Congreso Internacional sobre Investigación en la Didáctica de las Ciencias, 8., 2009. Barcelona. Atas... Barcelona: Universitad de Barcelona, v. 1, p. 438-441, 2009.

GOUGH, B.; FRY, G., GROGAN, S.; CONNER, M. Why do young adult smokers continue to smoke despite the health risks? A focus group study. Psychology \& Health, v. 24, n. 2, p. 203-220, 2009.

HOLZMAN, L. What Kind of Theory is Activity Theory? Introduction: Theory \& Psychology, v. 16, n. 1, p. 5-11, 2006.

ILYENKOV, E. V. The Ideal in Human Activity. Pacifica (CA): Marxists Internet Archive, 2009.

KIRSCHNER P. A.; SWELLER, J.; CLARK, R. E. Why Minimal Guidance During Instruction Does Not Work: An Analysis of the Failure of Constructivist, Discovery, Problem-Based, Experiential, and Inquiry-Based Teaching. Educational Psychologist, v. 41, n. 2, p. 75-86, 2006.

KOZULIN, A. O conceito de atividade na psicologia soviética: Vygotsky, seus discípulos, seus críticos. In: DANIELS, H. (Org.). Uma introdução a Vygotsky. São Paulo: Loyola, 2002. p. 111-138.

LEONTIEV, A. N. O desenvolvimento do psiquismo. São Paulo: Centauro Editora, 2004.

LIMA JUNIOR, P.; OSTERMANN, F.; REZENDE, F. Marxism in Vygotskian approaches to cultural studies of science education. Cultural Studies of Science Education (on line). DOI 10.1007/s11422-0139485-8. Disponível em: <http://link.springer.com/article/10.1007\%2Fs11422-013-9485-8>. Acesso em: 12 fevereiro 2014.

MARX, K. Introdução à Contribuição para a Crítica da Economia Política. Marxists Internet Archive, 1859.

. Manuscritos econômico-filosóficos. Lisboa: Edições 70, 1975.

O capital: crítica da economia política. Vol. 1, Livro primeiro: O processo de produção do capital. São Paulo: Boitempo Editorial, 2013.

MATTOS, C.R. O ABC da Ciência. In: GARCIA, N. M. D. et al. (Org.). A pesquisa em ensino de Física e a sala de aula: articulações necessárias. 1. ed. São Paulo: Sociedade Brasileira de Física, v. 1, p. 141-156, 2010.

MOREIRA, M. A. Ensino de Física no Brasil: Retrospectiva e Perspectivas. Revista Brasileira de Ensino de Física, São Paulo, v. 22, n. 1, p. 94-99, 2000.

MORTIMER, E.F.; SCOTT, P. Meaning Making in Secondary Science Classrooms. Philadelphia: Open University Press. 2003.

MOURA, M.A. Construção social da cidadania científica: desafios. In: (Org.). Educação científica e cidadania: abordagens teóricas e metodológicas para a formação de pesquisadores juvenis. Belo Horizonte: UFMG / PROEX, 2012. p. 19-30.

NACE - National Association of Colleges and Employers. Job outlook 2012. Bethlehem (PA): National Association of Colleges and Employers. 2011. Disponível em: <http:/ /www.uwsuper.edu/career/ students/upload/Job-Outlook-2012-Member-Version-1.pdf>. Acesso em: 12 fevereiro 2014.

. Job outlook 2013. Bethlehem (PA): National Association of Colleges and Employers. 2012. Disponível em <http://cbe.calstatela.edu/is/pdfs/NACEJobOutlook2013.pdf > . Acesso em: 12 fevereiro 2014.

NASCIMENTO, S.S; PLANTIN, C. (Org.). Argumentação e Ensino de Ciências. Curitiba: Editora CRV, 2009.

NIELSEN, J. A. Co-opting Science: A preliminary study of how students invoke science in valueladen discussions. International Journal of Science Education. v. 34, n. 2, p. 275-299, 2012.

NRC - National Research Council of the National Academies. National Science Education Standards. National Committee on Science Education Standards \& Assessment, National Research Council. Washington (D.C.): The National Academies Press. 1996.

NRC - National Research Council of the Nacional Academies. Taking Science to school: Learning and Teaching Science in Grades K-8. DUSCHL, R.A.; SCHWEINGRUBER, H.A.; SHOUSE, A.W. (Eds.). Washington (D.C.): The National Academies Press. 2007.

OECD - Organization for Economic Co-operation and Development. Assessing scientific, reading and mathematical literacy: a framework for PISA 2006. Paris: OECD. 2006.

PAZELLO, F.P.; MATTOS, C.R. O Conceito de Generalização: explorando os limites do modelo de perfil conceitual. In: Encontro de Pesquisa em Ensino de Física, 12., 2010. Águas de Lindóia. Atas... Águas de Lindóia: Sociedade Brasileira de Física, 2010. p. 1-12. 
PINTÓ, R.; COUSO, D. (Eds.). Contributions from Science Education Research. New York: Springer Verlag, 2007.

RODRIGUES, A.M. Redimensionando a noção de aprendizagem nas relações entre perfil conceitual e contexto: uma abordagem sócio-cultural-histórica. 2009. 158f. Dissertação (Mestrado em Ensino de Física) - Ensino de Ciências (Física, Química e Biologia), Universidade de São Paulo, São Paulo, 2009. Disponível em: <http://www.teses.usp.br/teses/disponiveis/81/81131/tde-23042013124053/>. Acesso em: 12 fevereiro 2014.

RODRIGUES, A.M.; MATTOS, C.R. Reflexões sobre a noção de significado em contexto. Indivisa, Boletin de Estudios e Investigación, v.7, p. 323-333, 2007.

RODRIGUES, A.M.; CAMILLO, J.; MATTOS, C.R. Quasi-appropriation of dialectical materialism: a critical reading of Marxism in Vygotskian approaches to cultural studies in science education. Cultural Studies of Science Education. No press. 2014.

ROTH, W.-M. Activity theory in education: An introduction. Mind, Culture, \& Activity, v. 11, n. 1, p. 1-8, 2004

ROTH, W.-M.; LEE, Y.-J.; HSU, P.-L. A tool for changing the world: possibilities of culturalhistorical activity theory to reinvigorate science education. Studies in Science Education, v. 45, n. 2, p. 131-167, 2009.

SALEM, S. Perfil, evolução e perspectivas da pesquisa em ensino de física no Brasil. 2012. Tese (Doutorado em Ensino de Física) - Ensino de Ciências (Física, Química e Biologia), Universidade de São Paulo, São Paulo, 2012. 385f. Disponível em: <http://www.teses.usp.br/teses/disponiveis/81/81131/ tde-13082012-110821/>. Acesso em: 12 fevereiro 2014.

SANNINO, A.; DANIELS, H.; GUTIÉRREZ, K. Activity theory between historical engagement and future-making practice. In: Cambridge: Cambridge Univ. Press, 2009. p.1-18.

SANTOS, F.P.P O conceito de generalização a partir de um olhar dialético-complexo sobre o modelo de perfil conceitual. 2011. 126f. Dissertação (Mestrado em Ensino de Física) - Ensino de Ciências (Física, Química e Biologia), Universidade de São Paulo, São Paulo, 2011. Disponível em: <http://www.teses.usp.br/ teses/disponiveis/81/81131/tde-31052012-104605/>. Acesso em: 12 fevereiro 2014.

SANTOS, F.M.T.; GRECA, M. I. (Orgs.). A pesquisa em ensino de ciências no Brasil e suas metodologias. 1. Ed. Ijuí: Editora Unijuí, 2008.

SMITH, E. Is there a crisis in school science education in the UK? Educational Review, v. 62, n. 2, p. 189-202, 2010.

SODRÉ, F.C.R.; MAT'TOS, C.R. Complexificando o conhecimento cotidiano: incluindo a física na problematização da alimentação. Alexandria, v. 6, p. 53-79, 2013.

TEIXEIRA, P.M.M.; MEGID NETO, J. O estado da arte da pesquisa em ensino de Biologia no Brasil: um panorama baseado na análise de dissertações e teses. Revista Electrónica de Enseñanza de las Ciencias, Vigo, Espanha v. 11, n. 2, p. 273-297, 2012.

VIGOTSKY, L.S. Pensamento e linguagem. São Paulo: Martins Fontes. 1987.

VYGOTSKY, L.S. A construção do pensamento e da linguagem. São Paulo: Editora Martins Fontes, 2001.

YANG, F.Y. Exploring high school students' use of theory and evidence in an everyday context: the role of scientific thinking in environmental science decision-making. International Journal of Science Education, v. 26, n. 11, p. 1345-1364, 2004.

YANG, F.Y.; ANDERSON, O.R. Senior high school students' preference and reasoning modes about nuclear energy use. International Journal of Science Education. v. 25, p. 221-244, 2003.

Data do Recebimento: 18/09/2013

Data da Aprovação: 24/01/2014

Data da Versão Final: 12/02/2014 